\title{
Project Management And Change Management

\author{
WORKING TOGETHER FOR EFFECTIVE ORGANIZATIONAL CHANGE
}

Megan K. Murray, Sarah Woodside, and Michael Braunscheidel

The BRC Academy Journal of Business 10, no. 1 (2019): 83-111.

http://dx.doi.org/10.15239/j.brcacadjb.2020.10.02.ja04

WEB APPENDIX

https://dx.doi.org/10.15239/j.brcacadjb.2020.10.01.wa04 
FIGURE 1: Project Management Book of Knowledge (PMBoK), 2009

\begin{tabular}{|c|c|c|c|c|c|}
\hline $\begin{array}{l}\text { Process Groups } \\
\text { Knowledge Area }\end{array}$ & Initiating & Planning & Executing & $\begin{array}{l}\text { Monitoring and } \\
\text { Controlling }\end{array}$ & Closing \\
\hline $\begin{array}{l}\text { 4. Project } \\
\text { Integration } \\
\text { Management }\end{array}$ & $\begin{array}{l}4.1 \text { Develop } \\
\text { Project } \\
\text { Charter }\end{array}$ & $\begin{array}{l}\text { 4.2 Develop Project Management } \\
\text { Plan }\end{array}$ & $\begin{array}{l}4.3 \text { Direct and Manage } \\
\text { Project Execution }\end{array}$ & $\begin{array}{l}\text { 4.4 Monitor and } \\
\text { Control Project Work } \\
\text { 4.5 Perform Integrated } \\
\text { Change Control }\end{array}$ & $\begin{array}{l}\text { 4.6 Close } \\
\text { Project or } \\
\text { Phase }\end{array}$ \\
\hline $\begin{array}{l}\text { 5. Project Scope } \\
\text { Management }\end{array}$ & & $\begin{array}{l}5.1 \text { Collect Requirements } \\
5.2 \text { Define Scope } \\
5.3 \text { Create WBS }\end{array}$ & & $\begin{array}{l}\text { 5.4 Verify Scope } \\
5.5 \text { Control Scope }\end{array}$ & \\
\hline $\begin{array}{l}\text { 6. Project Time } \\
\text { Management }\end{array}$ & & $\begin{array}{l}\text { 6.1 Define Activities } \\
\text { 6.2 Sequence Activities } \\
\text { 6.3 Estimate Activity Resources } \\
\text { 6.4 Estimate Activity Durations } \\
\text { 6.5 Develop Schedule }\end{array}$ & & 6.6 Control Schedule & \\
\hline $\begin{array}{l}\text { 7. Project Cost } \\
\text { Management }\end{array}$ & & $\begin{array}{l}\text { 7.1 Estimate Costs } \\
\text { 7.2 Determine Budget }\end{array}$ & & 7.3 Control Costs & \\
\hline $\begin{array}{l}\text { 8. Project Quality } \\
\text { management }\end{array}$ & & 8.1 Plan Quality & $\begin{array}{l}8.2 \text { Perform Quality } \\
\text { Assurance }\end{array}$ & $\begin{array}{l}\text { 8.3 Perform Quality } \\
\text { Control }\end{array}$ & \\
\hline $\begin{array}{l}\text { 9. Project Human } \\
\text { Resource } \\
\text { Management }\end{array}$ & & 9.1 Develop Human Resource Plan & $\begin{array}{l}\text { 9.2 Acquire Project Team } \\
\text { 9.3 Develop Project Team } \\
\text { 9.4 Manage Project Team }\end{array}$ & & \\
\hline $\begin{array}{l}\text { 10. Project } \\
\text { Communications } \\
\text { Management }\end{array}$ & $\begin{array}{l}10.1 \text { Identify } \\
\text { Stakeholders }\end{array}$ & 10.2 Plan Communications & $\begin{array}{l}\text { 10.3 Distribute Information } \\
10.4 \text { Manage Stakeholder } \\
\text { Expectations }\end{array}$ & $\begin{array}{l}\text { 10.5 Report } \\
\text { Performance }\end{array}$ & \\
\hline $\begin{array}{l}\text { 11. Project Risk } \\
\text { Management }\end{array}$ & & $\begin{array}{l}\text { 11.1 Plan Risk Management } \\
\text { 11.2 Identify Risks } \\
\text { 11.3 Perform Qualitative Risk } \\
\text { Analysis } \\
\text { 11.4 Perform Quantitative Risk } \\
\text { Analysis } \\
\text { 11.5 Plan Risk Responses }\end{array}$ & & $\begin{array}{l}11.6 \text { Monitor and } \\
\text { Control Risks }\end{array}$ & \\
\hline $\begin{array}{l}\text { 12. Project } \\
\text { Procurement } \\
\text { Management }\end{array}$ & & 12.1 Plan Procurements & $\begin{array}{l}12.2 \text { Conduct } \\
\text { Procurements }\end{array}$ & $\begin{array}{l}\text { 12.3 Administer } \\
\text { Procurements }\end{array}$ & $\begin{array}{l}12.4 \text { Close } \\
\text { Procurements }\end{array}$ \\
\hline
\end{tabular}


FIGURE 2: 8-Step Process For Leading Change, Kotter International, 1996

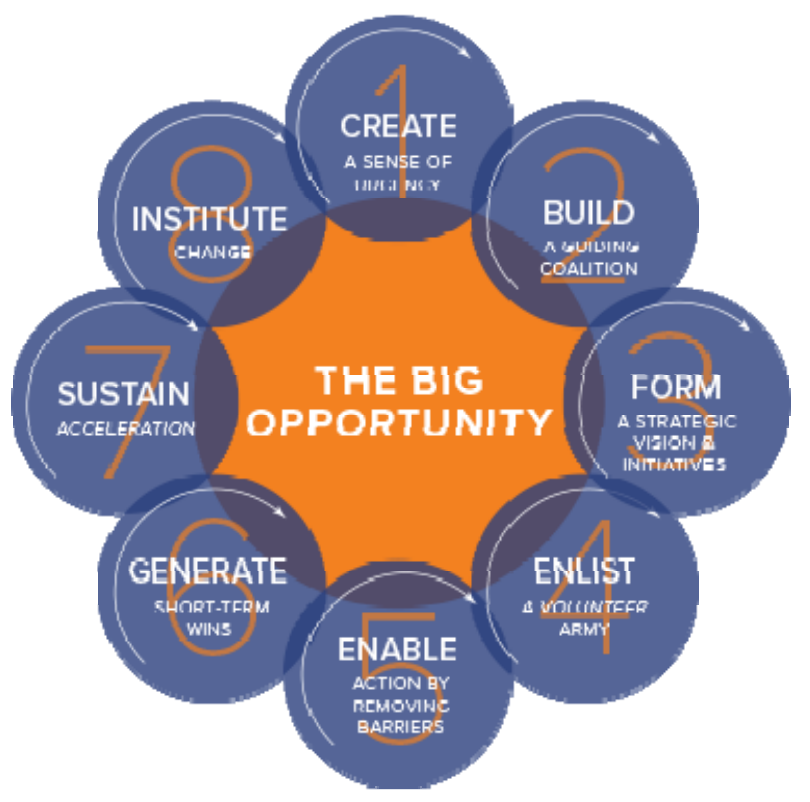


Figure 3: Case Study Data Mapped onto Project Management (PMBoK) and Kotter's Change Models

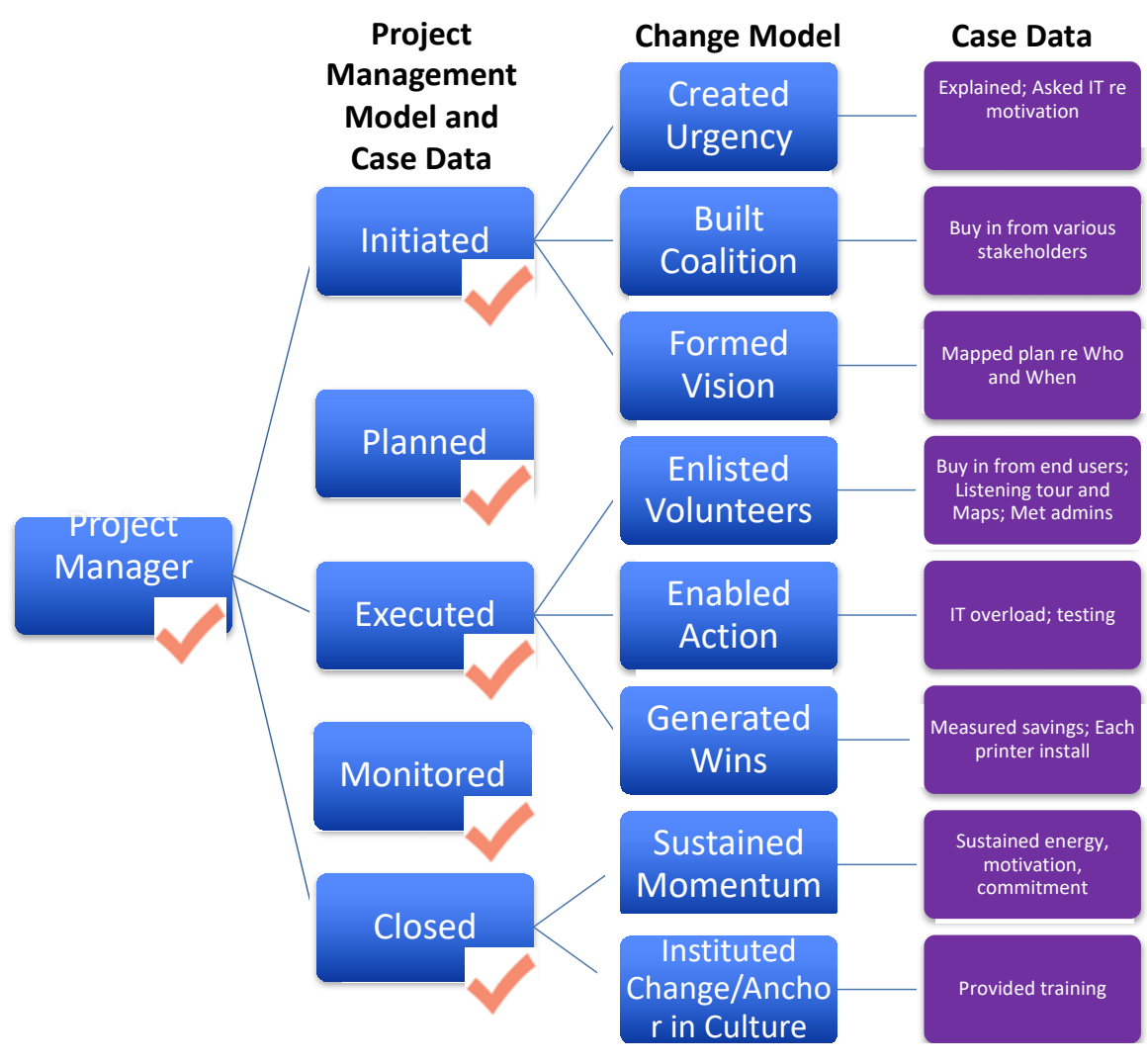


Figure 4: Expanded 8-Step Process for Leading Change

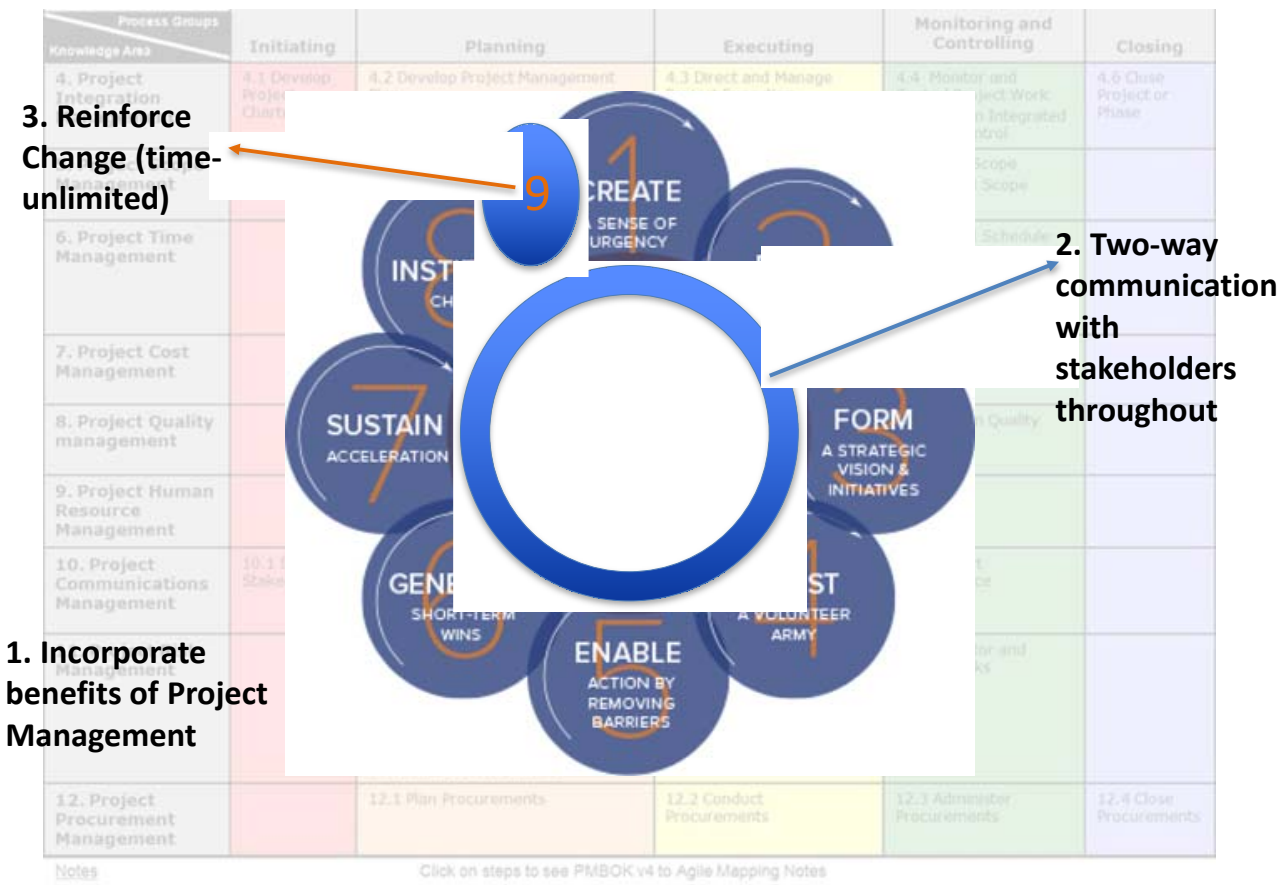

